\title{
Dynamics of a Duopoly Game with Two Different Delay Structures
}

\author{
Shumin Jiang, Fei Xu, Zhanwen Ding, Chen Yang, and Huanhuan Liu
}

Faculty of Science, Jiangsu University, Zhenjiang 212013, China

Correspondence should be addressed to Shumin Jiang; jsm@ujs.edu.cn

Received 23 March 2017; Revised 8 May 2017; Accepted 14 May 2017; Published 13 June 2017

Academic Editor: Douglas R. Anderson

Copyright (c) 2017 Shumin Jiang et al. This is an open access article distributed under the Creative Commons Attribution License, which permits unrestricted use, distribution, and reproduction in any medium, provided the original work is properly cited.

\begin{abstract}
Two different time delay structures for the dynamical Cournot game with two heterogeneous players are considered in this paper, in which a player is assumed to make decision via his marginal profit with time delay and another is assumed to adjust strategy according to the delayed price. The dynamics of both players output adjustments are analyzed and simulated. The time delay for the marginal profit has more influence on the dynamical behaviors of the system while the market price delay has less effect, and an intermediate level of the delay weight for the marginal profit can expand the stability region and thus promote the system stability. It is also shown that the system may lose stability due to either a period-doubling bifurcation or a Neimark-Sacker bifurcation. Numerical simulations show that the chaotic behaviors can be stabilized by the time-delayed feedback control, and the two different delays play different roles on the system controllability: the delay of the marginal profit has more influence on the system control than the delay of the market price.
\end{abstract}

\section{Introduction}

A monopoly market is the case where a trade is completely controlled by a small number of firms. The few firms produce the same or homogeneous products and they must take into account all the information in the market and the actions of the competitors. Cournot [1] first introduced the game model which gives a mathematical description of the dynamic competition in a duopoly market. In a classic Cournot model, each firm is assumed to have naive expectation and thus guesses that the opponent's output remains at the same level as in the previous period and then chooses a optimal production strategy in the current period. The classic research has paid much attention to the stability and the complex phenomena in the dynamics of a Cournot game played by players with naïve expectation (e.g., [2-8]).

Rather than the naive expectation, a so-called boundedly rationality based on players' marginal profits has received great attention in recent years. Bischi and Naimzada [9] first gave the general formula of bounded rationality in a duopoly game, where each firm uses the local knowledge of its marginal profit to adjust strategy in a new period: increasing its output if it perceives a positive marginal profit and decreasing its production if the perceived marginal profit is negative. A great deal of research work has been done for the dynamical Cournot game played by homogeneous players with such a kind of rationality (e.g., [9-12]).

Besides the work on the models with homogeneous players, there is another branch of literature that is interested in the games with heterogeneous players. The dynamic duopoly model with one boundedly rational player and one naïve player has been studied by Agiza and Elsadany [13]. By modifying the cost function in [13], Zhang et al. [14] studied the case with nonlinear cost function. A duopoly game with heterogeneous players and isoelastic demand function has been studied by Tramontana [15] and Angelini et al. [16]. Ma and Xie [17] considered the changing demand to develop the dynamic game models for the two scenarios and analyzed the model's dynamic behavior. In the model with two heterogeneous players, Fan et al. [18] supposed that the naive player does not know the rival's output and adjusts his 
production according to the previous market price. Ding et al. [19] studied a two-team game played by one team consisting of two boundedly rational players and one team consisting of a naïve player.

In the work on the dynamic Cournot model, time delay has also attracted the attention of many scholars. Many researches examine the effect of delay on dynamics. Onetime delay, two-time delay, continuously distributed time delay, and geometric delay are systematically reviewed and studied in [20-22], which offer results on existence, stability, and local bifurcations of the equilibrium points. Besides, the work in [23-28] studied the dynamical Cournot game with delayed bounded rationality and found that time delay can increase the system stability and delay the occurrence of complex behaviors. Ma and Si [29] also confirmed that the stability of the system depends on the delay and weight. The result showed that the stability of price was closely related to the parameters and the reasonable region of price benefited the firm profit. Further, $\mathrm{Ma}$ and $\mathrm{Wu}$ [30] studied the influence of parameter change on the market stability and chaos on the sensitivity level. By comparing parameter basin plots, the influences of decision parameters on the dynamics behaviors of the two models are further analyzed [31]. In [23-25, 27, 28] time delay is done for the output variable so that decision makers' expectations are based on the delayed data of their outputs, which implicitly means that any player must know each opponent's output in the previous periods. These models may not be suitable for the market with incomplete information where a decision maker has too limited knowledge to get the opponents' output data [26]. It is also pointed out [26] that any producer is able to know his own marginal profit, which is the profit of the last unit production and can be observed in its accounting. Then Ding et al. [26] considered a case that each player makes adjustment strategy according to the delayed marginal profit, the one that averages his own previous marginal profits with different weights. Besides the information of marginal profit, in this work we will consider another fact that the market price history is usually a common knowledge to every player. In the market, there may be players who simply make decision according to an expected price, for example, an average from several previous periods.

In this work, we reconsider the duopoly model in Ding et al. [26]. But different from [26] that only considers homogeneous players and only discusses the time delay structure built for the marginal profit, this paper revises the model and assumes that in the duopoly market the two players are heterogeneous and they consider different time delay structures. One player is still assumed to set delay on the marginal profit and thus adjusts strategy by weighting his marginal profits in the previous periods, as done in [26]. But another player is assumed to make decision according to an expected price that averages the price history with proper weights. For this kind of duopoly game with different delay structures, this paper establishes the dynamical system and discusses its dynamic properties form theoretical and numerical approaches.

\section{The Model}

2.1. Two Different Delay Structures. We assume that there are two firms producing homogeneous goods for sale and the total supply $Q=q_{1}+q_{2}$ determines the market price $p$ through an inverse demand function $p=P(Q)$. If $C_{i}\left(q_{i}\right)$ denotes the cost function of firm $i$, then the profit of firm $i$ will be given by

$$
\pi_{i}=q_{i} P\left(q_{1}+q_{2}\right)-C_{i}\left(q_{i}\right), \quad i=1,2 .
$$

Suppose that firm 1 adjusts its output with the same time delay structure as discussed in [26]. That is, firm 1 sets delay on the marginal profit $\partial \pi_{1} / \partial q_{1}$, and by weighting the marginal profit history

$$
\left.\frac{\partial \pi_{1}}{\partial q_{1}}\right|_{t},\left.\frac{\partial \pi_{1}}{\partial q_{1}}\right|_{t-1}, \ldots,\left.\frac{\partial \pi_{1}}{\partial q_{1}}\right|_{t-T},
$$

firm 1 updates its strategy in period $t+1$ according to the following equation (see [26]):

$$
q_{1}(t+1)=q_{1}(t)+\left.v q_{1}(t) \sum_{l=0}^{T} \alpha_{l} \frac{\partial \pi_{1}}{\partial q_{1}}\right|_{t-l},
$$

where $\alpha_{l} \geq 0$ is a weight coefficient to the delayed period $t-$ $l, \sum_{l=0}^{T} \alpha_{l}=1$, and $v$ is a positive constant representing the relative adjustment rate. As done in [26], we also consider a delay structure with one step: $T=1$, then (3) can be written as

$$
\begin{aligned}
q_{1}(t+1)= & q_{1}(t) \\
& +v q_{1}(t)\left[\left.\alpha \frac{\partial \pi_{1}}{\partial q_{1}}\right|_{t}+\left.(1-\alpha) \frac{\partial \pi_{1}}{\partial q_{1}}\right|_{t-1}\right],
\end{aligned}
$$

where $0 \leq \alpha \leq 1$ is the weight coefficient assigned to the nondelayed period $t$ and hence $1-\alpha$ is the one to the delayed period $t-1$.

Next, we consider firm 2 that is supposed to have a time delay structure built for the price history. In a real market, the market price is usually a common knowledge to all players so that the information of the price history

$$
p(t), p(t-1), \ldots, p(t-T)
$$

may be perceived by all of them. In our model, we suppose that in period $t+1$ firm 2 makes an expectation $p_{2}^{e}(t+1)$ for the market price, which averages the above price history with different weight coefficients and hence takes its form as

$$
p_{2}^{e}(t+1)=\sum_{l=0}^{T} \beta_{l} p(t-l)
$$

where $\beta_{l} \geq 0$ is the weight coefficient and $\sum_{l=0}^{T} \beta_{l}=1$. For player 2, we also consider the case of one step delay; that is,

$$
p_{2}^{e}(t+1)=\beta p(t)+(1-\beta) p(t-1)
$$


where $\beta$ is the weight to the nondelayed period $t$ and $1-\beta$ is associated with the delayed period $t-1$. From such a time delay structure, firm 2 may expect a profit $\pi_{2}^{e}(t+1)$ for its output choice $q_{2}(t+1)$ :

$$
\pi_{2}^{e}(t+1)=q_{2}(t+1) p_{2}^{e}(t+1)-C_{2}\left(q_{2}(t+1)\right) .
$$

It is supposed that in period $t+1$ firm 2 will make its decision in accordance with a best reply to the expected profit $\pi_{2}^{e}(t+1)$. That is, to maximize its expected profit $\pi_{2}^{e}(t+1)$ firm 2 will choose its output strategy $q_{2}(t+1)$ according to the following formula:

$$
q_{2}(t+1)=\arg \max _{q_{2}(t+1)} \pi_{2}^{e}(t+1) .
$$

2.2. The Dynamical System. For a duopoly game with two homogeneous players, Section 2.1 has built two different time delay structures and obtained (4) and (9), which describe two-dimensional and discrete dynamics:

$$
\begin{aligned}
q_{1}(t+1)= & q_{1}(t) \\
& +v q_{1}(t)\left[\left.\alpha \frac{\partial \pi_{1}}{\partial q_{1}}\right|_{t}+\left.(1-\alpha) \frac{\partial \pi_{1}}{\partial q_{1}}\right|_{t-1}\right], \\
q_{2}(t+1)= & \arg \max _{q_{2}(t+1)} \pi_{2}^{e}(t+1) .
\end{aligned}
$$

To give a specific form for dynamics (10), in our model we also assume linear inverse demand function $[5,9,10,13$, $14,18,23,24,26,32-34]$ :

$$
P(Q)=a-b Q
$$

and a quadratic form of cost function $[10,14,24,26]$ :

$$
C_{i}\left(q_{i}\right)=c_{i} q_{i}^{2} \quad(i=1,2)
$$

where $a, b$, and $c_{i}(i=1,2)$ are all positive. Then the profit of firm 1 is given by

$$
\pi_{1}=q_{1}\left[a-b\left(q_{1}+q_{2}\right)\right]-c_{1} q_{1}^{2}
$$

from which we obtain the marginal profit of firm 1 in period $t$ :

$$
\left.\frac{\partial \pi_{1}}{\partial q_{1}}\right|_{t}=a-2\left(b+c_{1}\right) q_{1}(t)-b q_{2}(t)
$$

And from firm 2's expected price in (7), the market price expression in (11), and the cost function $C_{2}$ in (12), we obtain firm 2's expected profit as follows:

$$
\begin{aligned}
& \pi_{2}^{e}(t+1)=q_{2}(t+1)\left[\beta\left(a-b\left(q_{1}(t)+q_{2}(t)\right)\right)\right. \\
& \left.\quad+(1-\beta)\left(a-b\left(q_{1}(t-1)+q_{2}(t-1)\right)\right)\right]-c_{2} q_{2}^{2}(t \\
& \quad+1),
\end{aligned}
$$

which gives a maximization solution

$$
\arg \max _{q_{2}(t+1)} \pi_{2}^{e}(t+1)=\frac{\beta\left[a-b\left(q_{1}(t)+q_{2}(t)\right)\right]+(1-\beta)\left[a-b\left(q_{1}(t-1)+q_{2}(t-1)\right)\right]}{2 c_{2}} .
$$

Taking (14) and (16) into (10), we obtain a dynamical system with one step delay:

$$
\begin{aligned}
& q_{1}(t+1)=q_{1}(t)+v q_{1}(t)\left[\alpha\left(a-2\left(b+c_{1}\right) q_{1}(t)-b q_{2}(t)\right)+(1-\alpha)\left(a-2\left(b+c_{1}\right) q_{1}(t-1)-b q_{2}(t-1)\right)\right] \\
& q_{2}(t+1)=\frac{\beta\left[a-b\left(q_{1}(t)+q_{2}(t)\right)\right]+(1-\beta)\left[a-b\left(q_{1}(t-1)+q_{2}(t-1)\right)\right]}{2 c_{2}} .
\end{aligned}
$$

To study dynamics (17) conveniently, we write $q_{3}(t)$ for $q_{1}(t-1)$ and $q_{4}(t)$ for $q_{2}(t-1)$; then we rewrite (17) as a fourdimensional system as follows:

$$
\begin{aligned}
& q_{1}(t+1)=q_{1}(t)+v q_{1}(t)\left[\alpha\left(a-2\left(b+c_{1}\right) q_{1}(t)-b q_{2}(t)\right)\right. \\
& \left.\quad+(1-\alpha)\left(a-2\left(b+c_{1}\right) q_{3}(t)-b q_{4}(t)\right)\right],
\end{aligned}
$$

$$
\begin{aligned}
& q_{2}(t+1) \\
& =\frac{\beta\left[a-b\left(q_{1}(t)+q_{2}(t)\right)\right]+(1-\beta)\left[a-b\left(q_{3}(t)+q_{4}(t)\right)\right]}{2 c_{2}}, \\
& q_{3}(t+1)=q_{1}(t), \\
& q_{4}(t+1)=q_{2}(t) \text {. }
\end{aligned}
$$




\section{Stability of the Equilibriums}

Letting $q_{i}(t+1)=q_{i}(t)(i=1,2,3,4)$ in system (18), we get two nonnegative equilibrium points:

$$
\begin{aligned}
& E^{0}=\left(0, \frac{a}{b+2 c_{2}}, 0, \frac{a}{b+2 c_{2}}\right), \\
& E^{*}=\left(q_{1}^{*}, q_{2}^{*}, q_{3}^{*}, q_{4}^{*}\right),
\end{aligned}
$$

where $q_{1}^{*}=q_{3}^{*}=2 a c_{2} /\left(b^{2}+4 c_{1} c_{2}+2 b c_{1}+4 b c_{2}\right)$, and $q_{2}^{*}=$ $q_{4}^{*}=\left(a b+2 a c_{1}\right) /\left(b^{2}+4 c_{1} c_{2}+2 b c_{1}+4 b c_{2}\right) \cdot E^{0}$ is a boundary point and $E^{*}$ is an interior equilibrium.

At an equilibrium point $\left(q_{1}, q_{2}, q_{3}, q_{4}\right)$, the Jacobian matrix of (18) takes its form as

$$
\begin{aligned}
& J\left(q_{1}, q_{2}, q_{3}, q_{4}\right) \\
& =\left(\begin{array}{cccc}
D & -\alpha b v q_{1} & -2 v q_{1}(1-\alpha)\left(b+c_{1}\right) & -b v(1-\alpha) q_{1} \\
-\frac{\beta b}{2 c_{2}} & -\frac{\beta b}{2 c_{2}} & -\frac{(1-\beta) b}{2 c_{2}} & -\frac{(1-\beta) b}{2 c_{2}} \\
1 & 0 & 0 & 0 \\
0 & 1 & 0 & 0
\end{array}\right),
\end{aligned}
$$

where $D=1-2\left(b+c_{1}\right) v q_{1} \alpha+v\left[\alpha\left(a-2\left(b+c_{1}\right) q_{1}-b q_{2}\right)+\right.$ $\left.(1-\alpha)\left(a-2\left(b+c_{1}\right) q_{3}-b q_{4}\right)\right]$.

We know that the local stability of an equilibrium point is determined by the eigenvalues of the above matrix. That is, an equilibrium $\left(q_{1}, q_{2}, q_{3}, q_{4}\right)$ will be stable if the inequality $|\lambda|<1$ holds for every eigenvalue $\lambda$ of the Jacobian matrix $J\left(q_{1}, q_{2}, q_{3}, q_{4}\right)$; it will be unstable if there exists an eigenvalue $\lambda$ such that $|\lambda|>1$. And in a discrete system, there maybe exist a critical case that $|\lambda| \leq 1$ holds for each eigenvalue $\lambda$ and $|\lambda|=1$ holds for at least one eigenvalue $\lambda$. In a critical case, the system may be stable or unstable, and it may be needed to check the high order items to discuss the system stability.

Taking the expression of the boundary point $E^{0}=$ $\left(0, a /\left(b+2 c_{2}\right), 0, a /\left(b+2 c_{2}\right)\right)$ into $(20)$, we have that the Jacobian matrix at $E^{0}$ is simply given by

$$
\begin{aligned}
& J\left(E^{0}\right) \\
& =\left(\begin{array}{cccc}
1+\frac{2 a v c_{2}}{b+2 c_{2}} & 0 & 0 & 0 \\
-\frac{\beta b}{2 c_{2}} & -\frac{\beta b}{2 c_{2}} & -\frac{(1-\beta) b}{2 c_{2}} & -\frac{(1-\beta) b}{2 c_{2}} \\
1 & 0 & 0 & 0 \\
0 & 1 & 0 & 0
\end{array}\right),
\end{aligned}
$$

which has four eigenvalues:

$$
\begin{aligned}
& \lambda_{1}=0, \\
& \lambda_{2}=\frac{b+2 c_{2}+2 a c_{2} v}{b+2 c_{2}}, \\
& \lambda_{3,4} \\
& =\frac{-\beta b^{2}-2 \beta b c_{2} \pm \sqrt{b}\left(b+2 c_{2}\right) \sqrt{-8 c_{2}+8 \beta c_{2}+\beta^{2} b}}{4 c_{2}\left(b+2 c_{2}\right)} .
\end{aligned}
$$

Since $\left|\lambda_{2}\right|>1$ holds evidently, we conclude that the boundary equilibrium $E^{0}$ is unstable.

Next we study the local stability of the interior equilibrium $E^{*}$. Notice that, at the interior point $E^{*}$, the item $\alpha\left(a-2\left(b+c_{1}\right) q_{1}^{*}-b q_{2}^{*}\right)+(1-\alpha)\left(a-2\left(b+c_{1}\right) q_{3}^{*}-b q_{4}^{*}\right)$ must be zero. Then from (20), we have

$$
J\left(E^{*}\right)=\left(\begin{array}{cccc}
1-2\left(b+c_{1}\right) v q_{1}^{*} \alpha & -\alpha b v q_{1}^{*} & -2\left(b+c_{1}\right)(1-\alpha) v q_{1}^{*} & -b(1-\alpha) v q_{1}^{*} \\
-\frac{\beta b}{2 c_{2}} & -\frac{\beta b}{2 c_{2}} & -\frac{(1-\beta) b}{2 c_{2}} & -\frac{(1-\beta) b}{2 c_{2}} \\
1 & 0 & 0 & 0 \\
0 & 1 & 0 & 0
\end{array}\right) \text {, }
$$

of which the characteristic polynomial $P(\lambda)=\lambda^{4}+p_{1} \lambda^{3}+$ $p_{2} \lambda^{2}+p_{3} \lambda+p_{4}$, where

$$
\begin{aligned}
p_{1}= & -1+\frac{\beta b}{2 c_{2}}+2\left(b+c_{1}\right) v q_{1}^{*} \alpha, \\
p_{2}= & \frac{b(1-2 \beta)}{2 c_{2}}+2\left(b+c_{1}\right) v q_{1}^{*}(1-\alpha) \\
& +\frac{b\left(b+2 c_{1}\right) v q_{1}^{*} \alpha \beta}{2 c_{2}}, \\
p_{3}= & \frac{b\left(b+2 c_{1}\right) v q_{1}^{*}(\alpha+\beta-2 \alpha \beta)}{2 c_{2}}+\frac{b(-1+\beta)}{2 c_{2}},
\end{aligned}
$$

$$
p_{4}=\frac{b\left(b+2 c_{1}\right) v q_{1}^{*}(-1+\alpha)(-1+\beta)}{2 c_{2}} .
$$

The local stability of $E^{*}$ is determined by the roots of $P(\lambda)$ : if all the roots lie inside the unit disk (i.e., $|\lambda|<1$ holds for ever root $\lambda$ ), then $E^{*}$ will be asymptotically locally stable. About a polynomial $P(\lambda)=\lambda^{4}+p_{1} \lambda^{3}+p_{2} \lambda^{2}+p_{3} \lambda+p_{4}$, the following three statements give the equivalent conditions for all the roots lie inside the unit disk (Schur-Cohn Criterion, see, e.g., [35]):

(i) $p(1)=1+p_{1}+p_{2}+p_{3}+p_{4}>0$.

(ii) $(-1)^{4} p(-1)=1-p_{1}+p_{2}-p_{3}+p_{4}>0$. 


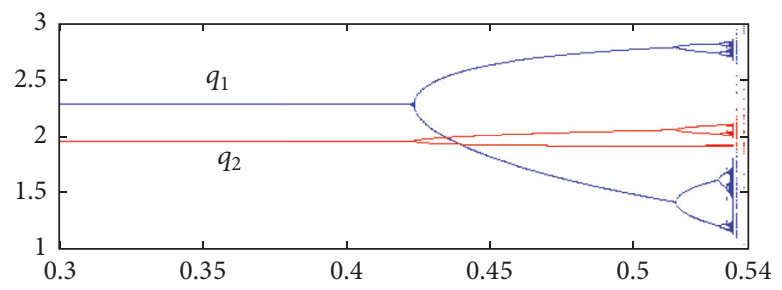

(a) $\alpha=0.9 ; \beta=0.2$

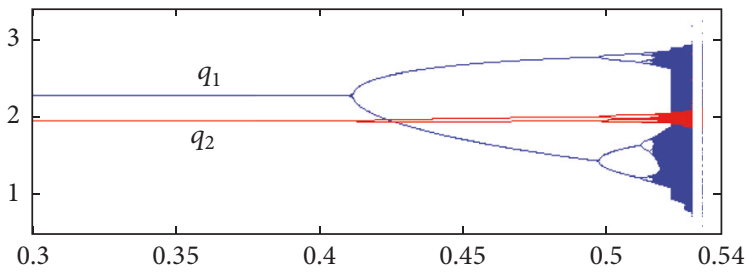

(b) $\alpha=0.9 ; \beta=0.6$

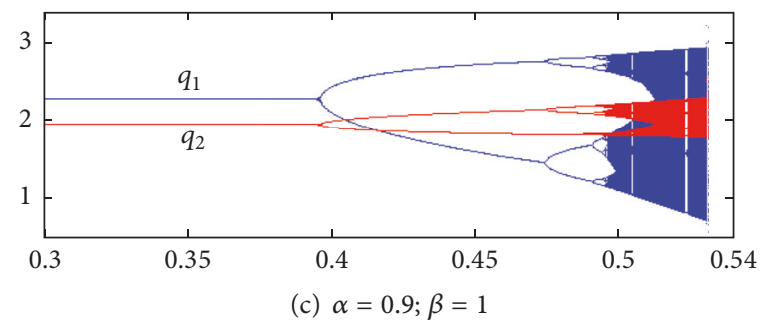

Figure 1: Bifurcation diagrams with respect to the adjustment speed $v$ for the same $\alpha$ and different $\beta$.

(iii) The determinants of the $1 \times 1$ matrices $B_{1}^{ \pm}$and the $3 \times 3$ matrices $B_{3}^{ \pm}$are all positive, where

$$
\begin{aligned}
B_{1}^{+}=\left(1+p_{4}\right), & \\
B_{1}^{-}=\left(1-p_{4}\right), & \\
B_{3}^{ \pm} & =\left(\begin{array}{lll}
1 & 0 & 0 \\
p_{1} & 1 & 0 \\
p_{2} & p_{1} & 1
\end{array}\right) \pm\left(\begin{array}{lll}
0 & 0 & p_{4} \\
0 & p_{4} & p_{3} \\
p_{4} & p_{3} & p_{2}
\end{array}\right) .
\end{aligned}
$$

In our model, $0 \leq \alpha \leq 1$ and $0 \leq \beta \leq 1$; then $1+p_{4}=$ $1+b\left(b+2 c_{1}\right) v q_{1}^{*}(1-\alpha)(1-\beta) / 2 c_{2}$ is obviously positive and by calculating we get

$$
\begin{aligned}
1+ & p_{1}+p_{2}+p_{3}+p_{4} \\
& =2\left(b+c_{1}\right) v q_{1}^{*}+\frac{b\left(b+2 c_{1}\right) v q_{1}^{*}}{2 c_{2}}
\end{aligned}
$$

which tells that $p(1)>0$ holds also. So we conclude that in our model the equilibrium $E^{*}$ will be asymptotically stable if $1-p_{1}+p_{2}-p_{3}+p_{4}>0,1-p_{4}>0, \operatorname{Det}\left(B_{3}^{+}\right)>0$ and $\operatorname{Det}\left(B_{3}^{-}\right)>$ 0 . These conditions can be reduced to the following inequality systems:

$$
\begin{aligned}
& \text { (S1) } p_{1}-p_{2}+p_{3}-1<p_{4}<1 \\
& \text { (S2) }-1-p_{1} p_{3} p_{4}+p_{4}^{2}+p_{2} p_{4}^{2}+p_{3}^{2}<p_{2}+p_{4}-p_{1} p_{3}+p_{1}^{2} p_{4}- \\
& p_{4}^{3}<1+p_{1} p_{3} p_{4}+2 p_{2} p_{4}-p_{4}^{2}-p_{2} p_{4}^{2}-p_{3}^{2}
\end{aligned}
$$

If the inequalities in (S1) and (S2) are all satisfied, then the equilibrium $E^{*}$ will be locally asymptotically stable in the evolution of (18). If these conditions fail to hold, then the system may lose stability and even exhibit much complicated dynamical behaviors, which will be shown in the following section of numerical simulation.

\section{Numerical Simulation}

In this section, the constants $a, b, c_{1}$, and $c_{2}$ are fixed and the different influence of the two delay weights $\alpha$ and $\beta$ on the system stability are simulated. The complicated dynamical behaviors are shown when the system loses its stability. Simply, in the next numerical simulations, the constants $a, b$, $c_{1}$, and $c_{2}$ are fixed as $a=7, b=0.5, c_{1}=0.82$, and $c_{2}=1.25$.

4.1. The Influence of the Delay Weight $\beta$. In Figure 1, for different $\beta$ and the same $\alpha$ with respect to the adjustment speed $v$, the delay weight $\alpha$ (by player 1 for the marginal profit) is fixed as 0.9 and the bifurcation diagrams are plotted for different $\beta$ (the delay weight by player 2 for the market price): $\beta=0.2,0.6,1$. We find that the system will be stable when the value of the adjustment speed $v$ stays at a low level, while when $v$ increases, the system will lose stability through bifurcations. Comparing the three diagrams in Figure 1, there is little difference in the values of $v$ for the system to lose stability.

To study the influence of the delay weight $\beta$ further, the stability regions of the system are shown in Figure 2 for four different values of $\beta(\beta=0.2,0.6,0.75,1)$. From Figure 2 , we see that the stability regions for different $\beta$ have little distinction for different $\beta$.

4.2. The Influence of the Delay Weight $\alpha$. Figure 3 fixes the weight $\beta=0.9$ and plots the bifurcation diagrams for different $\alpha$ : $\alpha=0.2,0.6,1$. From Figure 3, we see that the system will be stable when the value of the adjustment speed $v$ stays at a low level, while when $v$ increases, the system will lose stability through bifurcations. Comparing the three diagrams in Figure 1 done for different $\alpha$, we find that the point $v$ causing the stability loss is much more distinguishable.

The stability regions of the system are shown in Figure 4 for four different values of $\alpha(\alpha=0.2,0.6,0.75,1)$. By numerical simulations, Figure 4 shows clearly that the delay weight $\alpha$ has great effect on the system stability. It is also 

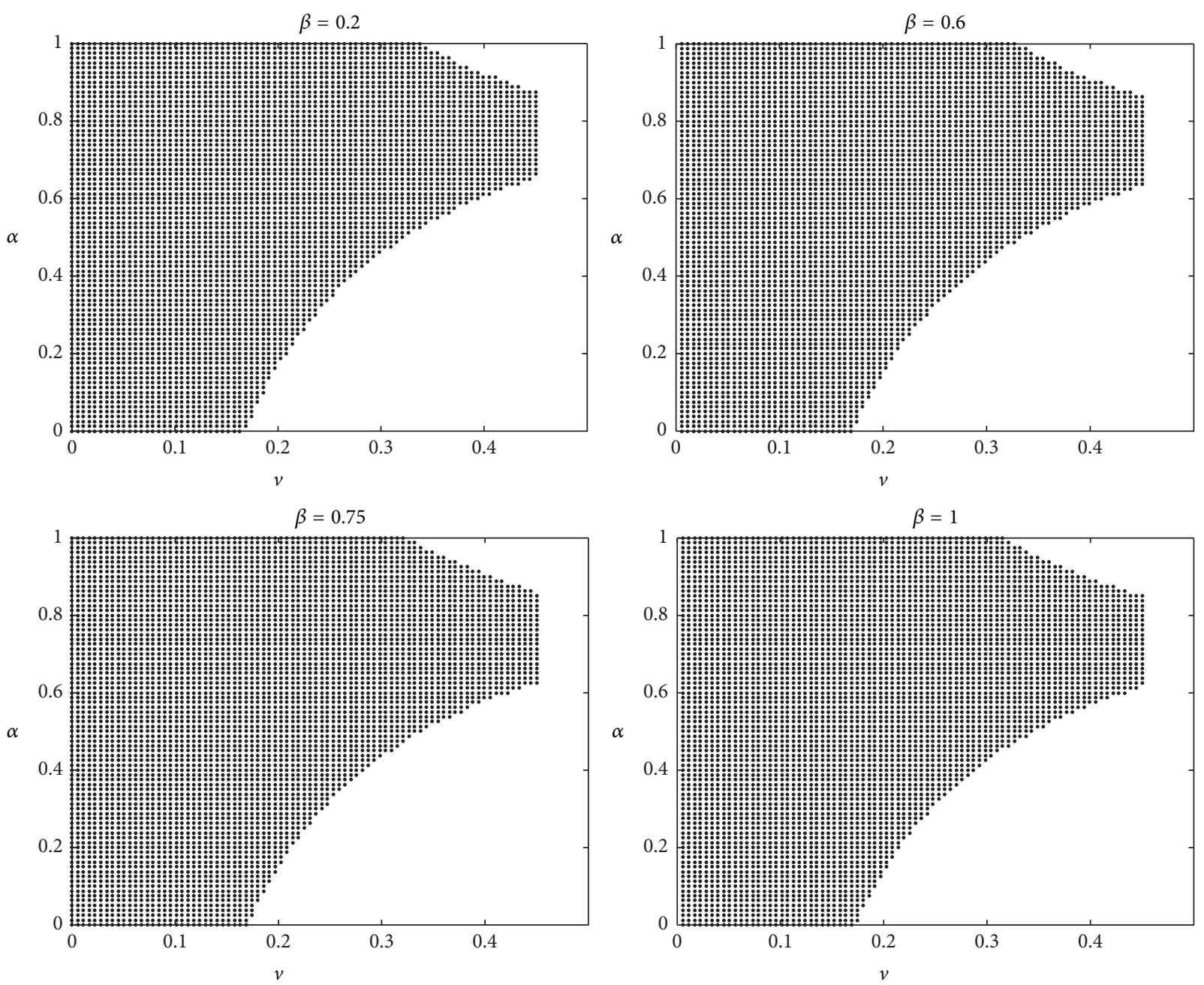

FIGURE 2: Stability regions in the $(v, \alpha)$-plane for different levels of $\beta$.
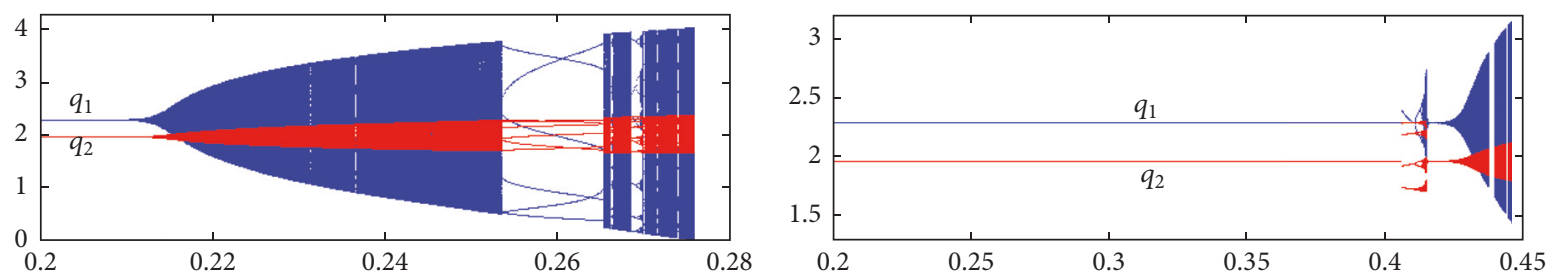

(a) $\beta=0.9 ; \alpha=0.2$

(b) $\beta=0.9 ; \alpha=0.6$

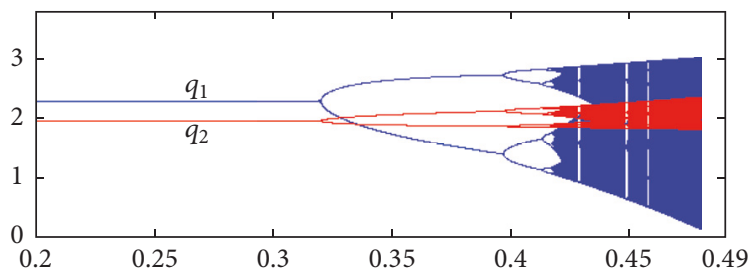

(c) $\beta=0.9 ; \alpha=1$

FIgURE 3: Bifurcation diagrams with respect to the adjustment speed $v$ for the same $\beta$ and different $\alpha$. 

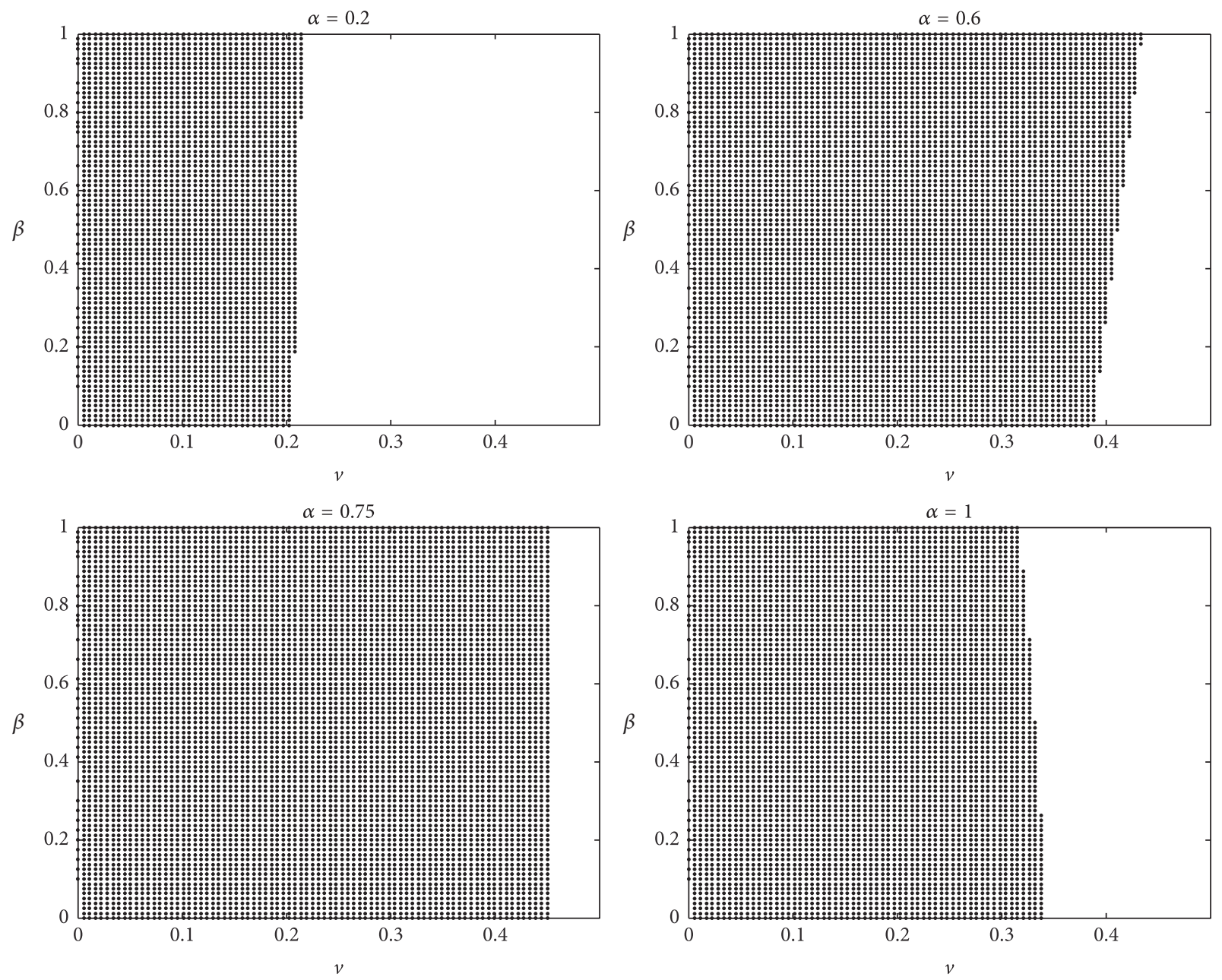

FIGURE 4: Stability regions in the $(v, \beta)$-plane for different levels of $\alpha$.

observed that the stability region for an intermediate level of $\alpha$ is larger than the one for the nondelayed case $(\alpha=0)$ and the full delayed case $(\alpha=1)$. That is, an intermediate marginal profit delay weight will promote the system stability (which is a result similar to the one obtained in the homogeneousplayers model [26]).

Comparing Figures 1 and 2, we say that the marginal profit delay weight $\alpha$ has more influence on the dynamical behavior of the system but the market price delay weight $\beta$ has less effect. And comparing Figures 3 and 4, it is clear that the delay weight $\beta$ plays little role in the system stability while the delay weight $\alpha$ has great effect.

4.3. Complexity of the System. As is shown in Figures 1 and 3, the system may lose stability through a process of bifurcation when the stability conditions are broken. From the two figures, we also find that the system stability loss occurs in two different ways. Indeed, in Figures 1(a), 1(b), 1(c), and 3(c), the system loses stability through a period-doubling bifurcation, whereas in Figures 3(a) and 3(b) the stability loss is evidently due to a Neimark-Sacker bifurcation. For this observation, we can give visually displays by two-dimensional phase portraits. For instance, four phase portraits of the trajectories $q_{1}$ and $q_{2}$ associated with Figure 1(b) are plotted in the first line of Figure 5 and the ones associated with Figure 3(a) are plotted in the second line. The first line of phase portraits evidently shows that in the stability loss process there are periods $1,2,4, \ldots$, which is a doubling bifurcation process and at last drives the system to chaos. The second line shows a typical Neimark-Sacker bifurcation process, where closed invariant curves take place when the system loses stability.

\section{Chaos Control}

We know that chaos is not desirable in a real economic system and it is often hoped to be controlled so that the dynamic system could run in a stable status. In this section, we show that the usually used method of time-delayed feedback control (e.g., [32, 36-38]) can also be used to control the chaos in our model.

Using the time-delayed feedback control method, we adjust (18) by inserting a control $k_{i}(q(t)-q(t+1))$ into the 

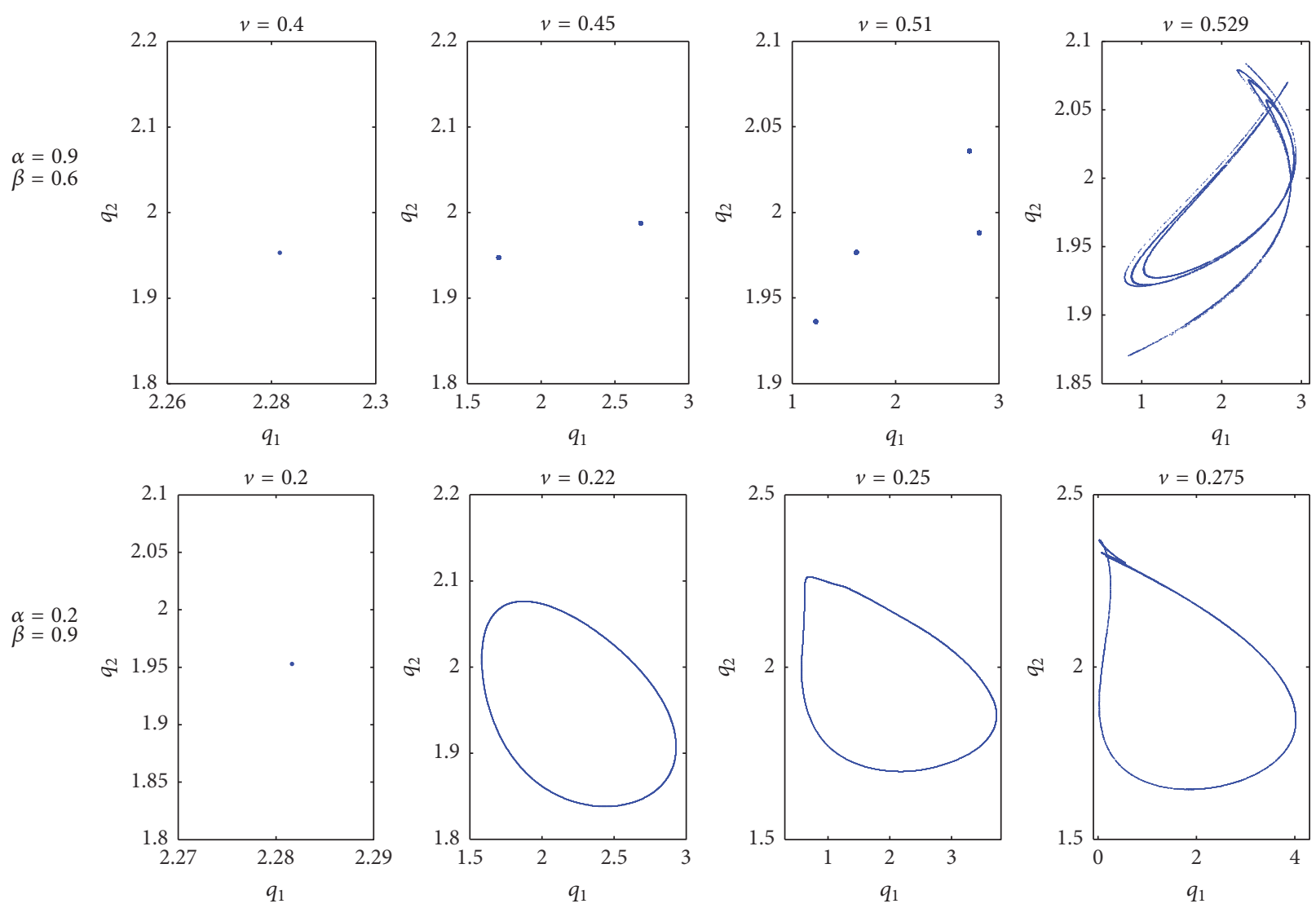

FIgURE 5: Phase portrait for Figure 1 with various $\alpha, \beta$, and $v$.

right hands of the first two equations, where $k_{i}>0$ is the controlling coefficient. Then we get a controlled system as follows:

$$
\begin{aligned}
& q_{1}(t+1)=q_{1}(t)+v q_{1}(t)\left[\alpha\left(a-2\left(b+c_{1}\right) q_{1}(t)-b q_{2}(t)\right)\right. \\
& \left.\quad+(1-\alpha)\left(a-2\left(b+c_{1}\right) q_{3}(t)-b q_{4}(t)\right)\right]+k_{1}\left(q_{1}(t)\right. \\
& \left.\quad-q_{1}(t+1)\right),
\end{aligned}
$$

$$
\begin{aligned}
& q_{2}(t+1) \\
& \quad=\frac{\beta\left[a-b\left(q_{1}(t)+q_{2}(t)\right)\right]+(1-\beta)\left[a-b\left(q_{3}(t)+q_{4}(t)\right)\right]}{2 c_{2}} \\
& \quad+k_{2}\left(q_{2}(t)-q_{2}(t+1)\right), \\
& q_{3}(t+1)=q_{1}(t), \\
& q_{4}(t+1)=q_{2}(t),
\end{aligned}
$$

which can be rewritten as

$$
\begin{aligned}
& q_{1}(t+1)=q_{1}(t)+\frac{1}{1+k_{1}} v q_{1}(t)\left[\alpha\left(a-2\left(b+c_{1}\right) q_{1}(t)-b q_{2}(t)\right)+(1-\alpha)\left(a-2\left(b+c_{1}\right) q_{3}(t)-b q_{4}(t)\right)\right] \\
& q_{2}(t+1)=\frac{\beta\left[a-b\left(q_{1}(t)+q_{2}(t)\right)\right]+(1-\beta)\left[a-b\left(q_{3}(t)+q_{4}(t)\right)\right]+2 c_{2} k_{2} q_{2}(t)}{2 c_{2}\left(1+k_{2}\right)} \\
& q_{3}(t+1)=q_{1}(t) \\
& q_{4}(t+1)=q_{2}(t) .
\end{aligned}
$$

It is obvious that controlled system (29) and (30) has the same equilibrium points as original system (18). At the interior equilibrium $E^{*}=\left(q_{1}^{*}, q_{2}^{*}, q_{3}^{*}, q_{4}^{*}\right)$, the Jacobian matrix of system (30) takes its form as 


$$
\left(\begin{array}{cccc}
1-\frac{2\left(b+c_{1}\right) v \alpha q_{1}^{*}}{1+k_{1}} & -\frac{b v \alpha q_{1}^{*}}{1+k_{1}} & -\frac{2\left(b+c_{1}\right) v(1-\alpha) q_{1}^{*}}{1+k_{1}} & -\frac{b v(1-\alpha) q_{1}^{*}}{1+k_{1}} \\
-\frac{\beta b}{2 c_{2}\left(1+k_{2}\right)} & \frac{2 c_{2} k_{2}-\beta b}{2 c_{2}\left(1+k_{2}\right)} & -\frac{(1-\beta) b}{2 c_{2}\left(1+k_{2}\right)} & -\frac{(1-\beta) b}{2 c_{2}\left(1+k_{2}\right)} \\
1 & 0 & 0 & 0 \\
0 & 1 & 0 & 0
\end{array}\right) .
$$

By a similar approach in Section 3 to get the stability conditions (S1)-(S2) for the original system (18), we can also give the stability conditions of controlled system (30) as follows:

$$
\begin{aligned}
& \text { (S3) } u_{1}-u_{2}+u_{3}-1<u_{4}<1 \\
& \text { (S4) }-1-u_{1} u_{3} u_{4}+u_{4}^{2}+u_{2} u_{4}^{2}+u_{3}^{2}<u_{2}+u_{4}-u_{1} u_{3}+u_{1}^{2} u_{4}-u_{4}^{3}< \\
& \quad 1+u_{1} u_{3} u_{4}+2 u_{2} u_{4}-u_{4}^{2}-u_{2} u_{4}^{2}-u_{3}^{2},
\end{aligned}
$$

where

$$
\begin{aligned}
& u_{1}=-1+\frac{2\left(b+c_{1}\right) v q_{1}^{*} \alpha}{1+k_{1}}-\frac{2 c_{2} k_{2}-b \beta}{2 c_{2}\left(1+k_{2}\right)}, \\
& u_{2}=\frac{2\left(b+c_{1}\right) v q_{1}^{*}(1-\alpha)}{1+k_{1}}+\frac{b(1-\beta)}{2 c_{2}\left(1+k_{2}\right)} \\
& -\frac{b^{2} v q_{1}^{*} \alpha \beta}{2 c_{2}\left(1+k_{1}\right)\left(1+k_{2}\right)}+\frac{2 c_{2} k_{2}-b \beta}{2 c_{2}\left(1+k_{2}\right)} \\
& -\frac{\left(b+c_{1}\right) v q_{1}^{*}\left(2 c_{2} k_{2}-b \beta\right) \alpha}{c_{2}\left(1+k_{1}\right)\left(1+k_{2}\right)}, \\
& u_{3}=-\frac{b^{2} v q_{1}^{*} \alpha(1-\beta)}{2 c_{2}\left(1+k_{1}\right)\left(1+k_{2}\right)}-\frac{b(1-\beta)}{2 c_{2}\left(1+k_{2}\right)} \\
& +\frac{2 b\left(b+c_{1}\right) v q_{1}^{*} \alpha(1-\beta)}{2 c_{2}\left(1+k_{1}\right)\left(1+k_{2}\right)} \\
& -\frac{b^{2} v q_{1}^{*} \beta(1-\alpha)}{2 c_{2}\left(1+k_{1}\right)\left(1+k_{2}\right)} \\
& -\frac{\left(b+c_{1}\right) v q_{1}^{*}\left(2 c_{2} k_{2}-b \beta\right)(1-\alpha)}{c_{2}\left(1+k_{1}\right)\left(1+k_{2}\right)}, \\
& u_{4}=-\frac{b^{2} v q_{1}^{*}(1-\alpha)(1-\beta)}{2 c_{2}\left(1+k_{1}\right)\left(1+k_{2}\right)} \\
& +\frac{b\left(b+c_{1}\right) v q_{1}^{*}(1-\alpha)(1-\beta)}{c_{2}\left(1+k_{1}\right)\left(1+k_{2}\right)} .
\end{aligned}
$$

To show the availability of the control method, we consider the case $\left(a, b, c_{1}, c_{2}, \alpha, \beta, v\right)=(7,0.5,0.82,1.25,0.9,1$, $0.53)$. Figure $1(\mathrm{c})$ shows that for this parameter group original system (18) exhibits chaotic behaviors in its evolution process. For controlled system (30) with this group of parameters unchanged and $k_{2}=0$, Figure 6 plots a bifurcation diagram with respect to the controlling coefficient $k_{1}$. It is observed that the controlled system will get out of chaos and be asymptotically locally stable once the controlling coefficient $k_{1}$ is increased to about 0.34 . Theoretically, if we take these parameter values into the stability conditions (S3) and (S4), we can obtain that the condition for the system which is locally asymptotically stable will be $k_{1}>0.337438$.

Below we numerically check the $\left(k_{1}, k_{2}\right)$ regions determined by stability conditions (S3) and (S4) for more chaos control situations. Figure 1 shows that when $\alpha=0.9, \beta=$ $0.2 / 0.6 / 1$, and $v=0.535 / 0.52 / 0.53$, the original system will be chaotic; Figure 2 shows that when $\beta=0.9, \alpha=$ $0.2 / 0.6 / 1$, and $v=0.275 / 0.44 / 0.46$, system (18) will also exhibit complicated behaviors. But stability conditions (S3) and (S4) tell that controlled system (30) will be stable, once the controlling coefficients $k_{1}$ and $k_{2}$ are set to meet the inequalities in (S3) and (S4). As numerical solutions of the inequality system (S3) and (S4), Figures 7 and 8 plot the $\left(k_{1}, k_{2}\right)$ regions for all the cases mentioned. Figures 7 and 8 mean that in each case the system chaos will be controlled if the controlling coefficients $k_{1}$ and $k_{2}$ together lie within the plotted regions. Figure 7 is done for different levels of $\beta$ and Figure 8 is done for different levels of $\alpha$. By comparing the three cases in Figure 7, we observe that there is little difference among the $\left(k_{1}, k_{2}\right)$ stability regions. That is, there is little change in the system controllability when $\beta$ is set at varied levels. However, from Figure 8 we see that $\alpha$ has great influence on the system controllability: the $\left(k_{1}, k_{2}\right)$ stability region for a more intermediate $\alpha$ is much larger so that the system can be more easily controlled. By these observations we draw one more conclusion that in our model the two different delays play also different roles on the system controllability: the delay of the marginal profit has more influence on the system control than the delay of the market price, and an intermediate level of delay for the marginal profit has a positive effect on the chaos control.

\section{Conclusion}

In this paper, we reconsider the duopoly game with time delay and formulate a model with two different delay structures. The main consideration is that the price history may be observed by all players in the market and there may be players making decision according to the historic information of the market price. In this work, we modify the model in [26] (where the two players are assumed to be homogeneous so that both players make decision according to the profit average with time delay). We assume that there are two 


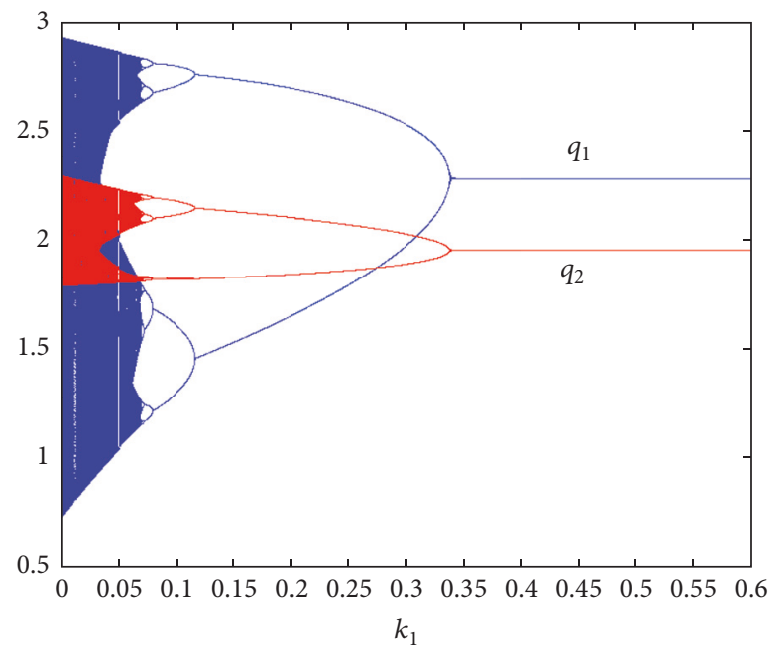

FIGURE 6: Bifurcation diagram with respect to $k_{1}$.
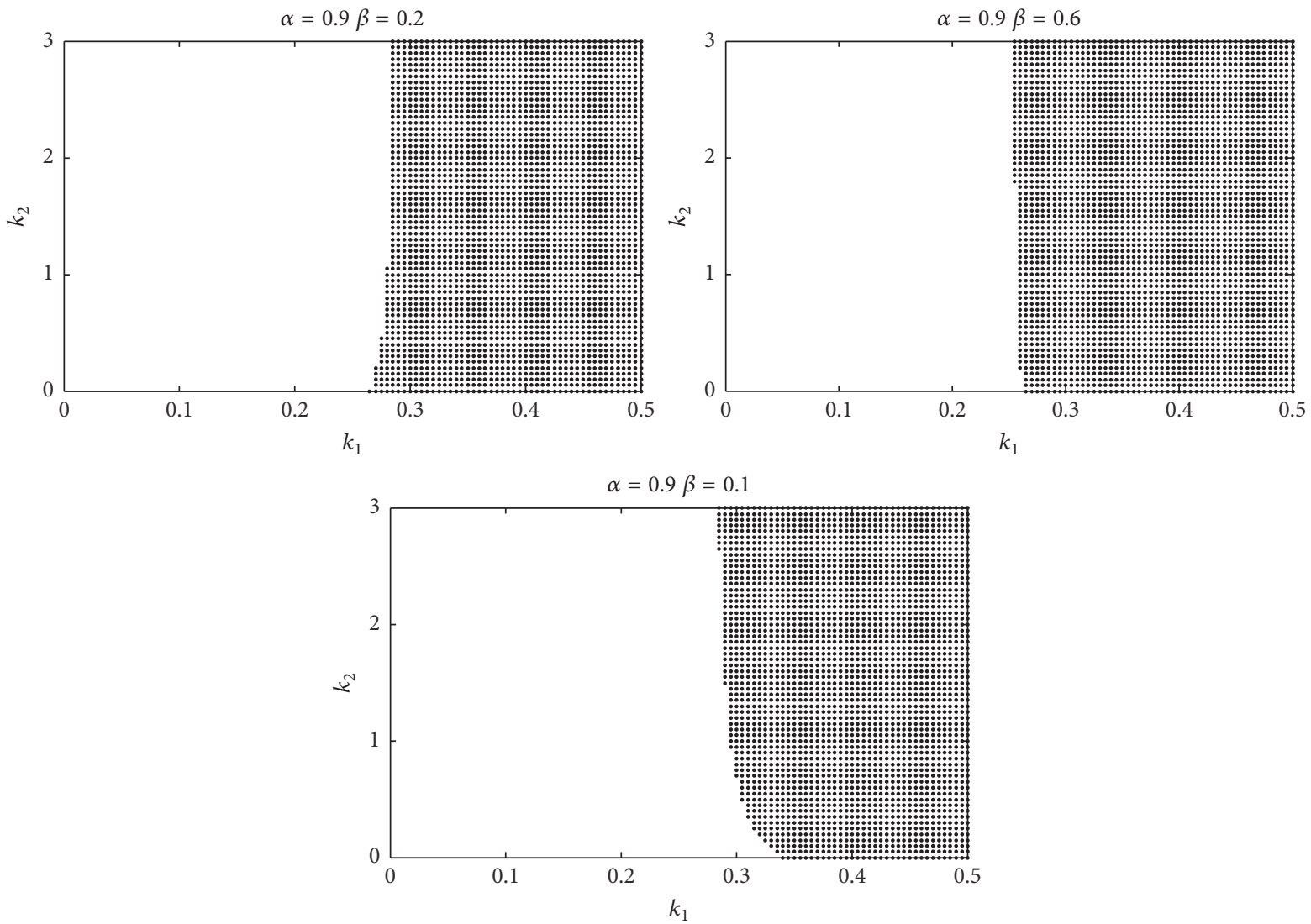

FIGURE 7: Stability regions in the $\left(k_{1}, k_{2}\right)$-plane for different levels of $\beta$.

different kinds of producers: one sets time delay on its marginal profit so that it adjusts its output by the approach discussed in [26]; but another sets time delay on the price variable and makes decision in accordance with the averaged data from the price history.

The dynamics of the players' output adjustments has been established, the equilibrium solutions are obtained, and the stability of the equilibriums is mathematically analyzed.
The boundary equilibrium is proved to be unstable and the stability conditions for the interior equilibrium are obtained. Numerical simulations are done to show the influence of the main model parameters on the system stability and on the complicated behaviors of the system when losing stability. It is observed that there is difference in the roles played by the two delay structures. The time delay for the marginal profit has more influence on the dynamical behaviors of 

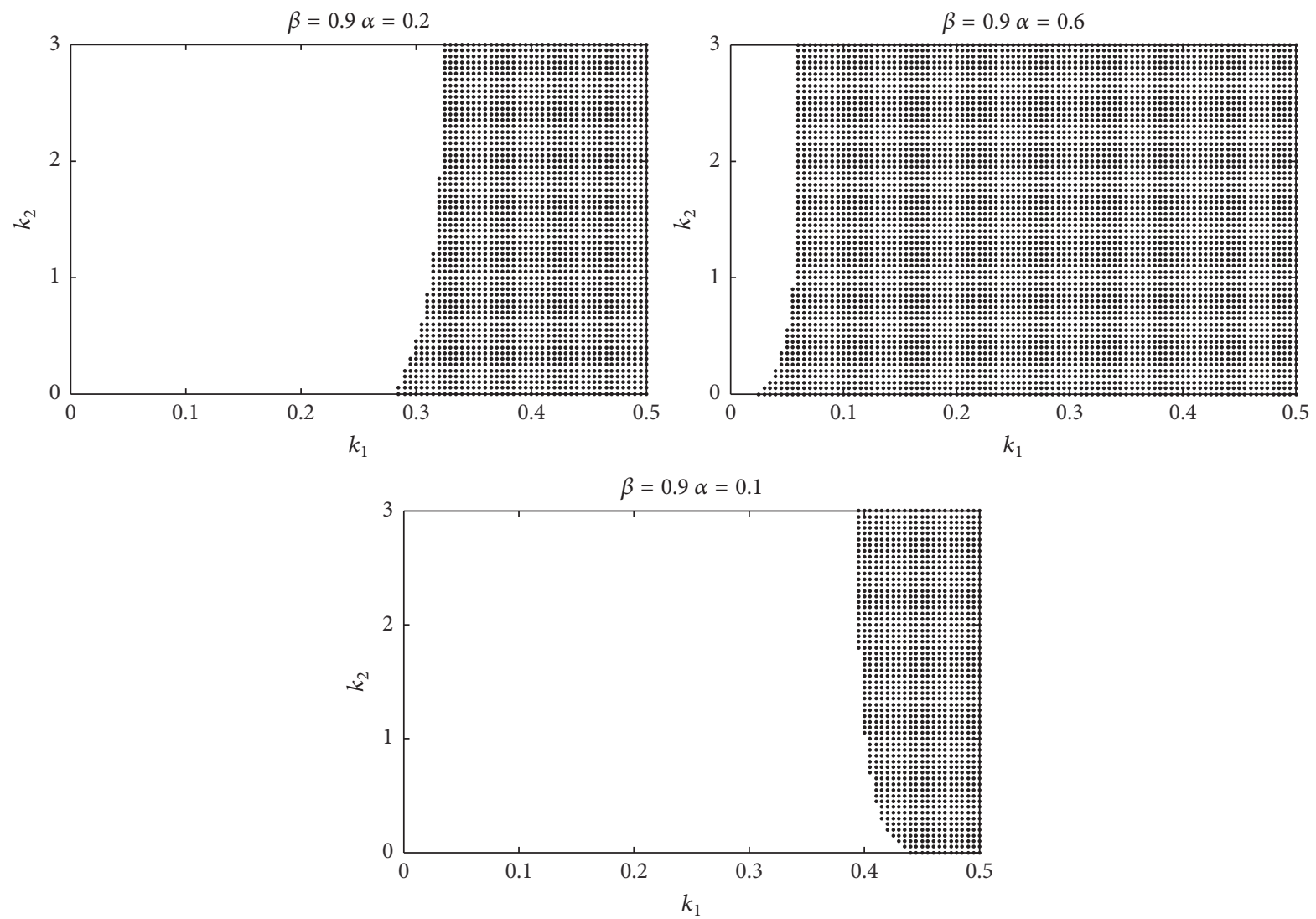

FIGURE 8: Stability regions in the $\left(k_{1}, k_{2}\right)$-plane for different levels of $\alpha$.

the system but the market price delay has less effect. An intermediate level of the delay weight for the marginal profit can promote the system stability and thus reduce the occurrence of complex behavior such as bifurcation and chaos. It is shown that the system stability losing may be due to either period-doubling bifurcations or Neimark-Sacker bifurcations. Numerical simulations show that the chaotic behaviors can be stabilized by the time-delayed feedback control, and the two different delays play also different roles in the system controllability: the delay for the marginal profit has more influence on the system control than the delay for the market price, and an intermediate level of delay for the marginal profit has a positive effect on the chaos control.

\section{Conflicts of Interest}

The authors declare that they have no conflicts of interest.

\section{Acknowledgments}

Financial support by the National Natural Science Foundation of China (nos. 71171098, 51306072, 71690242, and $71273120)$ is gratefully acknowledged.

\section{References}

[1] A. A. Cournot, Researches into the Mathematical Principles of the Theory of Wealth, Hachette, Paris, 1838.
[2] H. N. Agiza, "Explicit stability zones for Cournot game with 3 and 4 competitors," Chaos, Solitons \& Fractals, vol. 9, pp. 19551966, 1998.

[3] A. Agliari, L. Gardini, and T. Puu, "The dynamics of a triopoly Cournot game," Chaos, Solitons \& Fractals, vol. 11, pp. 25312560, 2000.

[4] E. Ahmed and H. N. Agiza, "Dynamics of a Cournot game with n-competitors," Chaos, Solitons \& Fractals, vol. 9, pp. 1513-1517, 1998.

[5] M. Kopel, "Simple and complex adjustment dynamics in Cournot duopoly models," Chaos, Solitons \& Fractals, vol. 7, pp. 2031-2048, 1996.

[6] T. Puu, "Complex dynamics with three oligopolists," Chaos, Solitons \& Fractals, vol. 7, pp. 2075-2081, 1996.

[7] T. Puu, "The chaotic duopolists revisited," Journal of Economic Behavior \& Organization, vol. 33, pp. 385-394, 1998.

[8] J. B. Rosser Jr., "The development of complex oligopoly dynamics theory," in Oligopoly Dynamics: Models and Tools, T. Puu and I. Sushko, Eds., pp. 15-29, Springer, Berlin, Germany, 2002.

[9] G. I. Bischi and A. Naimzada, "Global analysis of a dynamic duopoly game with bounded rationality," in Proceedings of the of the Annuals of International Society of Dynamic Games on Advances in Dynamic Games and Applications, J. A. Filar, V. Gaitsgory, and K. Mizukami, Eds., vol. volume 5, pp. 361-385, Birkhauser, Massachusetts, Mass, USA, 2000.

[10] H. N. Agiza, A. S. Hegazi, and A. A. Elsadany, "The dynamics of Bowley's model with bounded rationality," Chaos, Solitons \& Fractals, vol. 12, pp. 1705-1717, 2001. 
[11] H. N. Agiza, A. S. Hegazi, and A. A. Elsadany, "Complex dynamics and synchronization of a duopoly game with bounded rationality," Mathematics and Computers in Simulation, vol. 58, no. 2, pp. 133-146, 2002.

[12] E. Ahmed, H. N. Agiza, and S. Z. Hassan, "On modifications of Puu's dynamical duopoly," Chaos, Solitons \& Fractals, vol. 11, pp. 1025-1028, 2000.

[13] H. N. Agiza and A. A. Elsadany, "Nonlinear dynamics in the Cournot duopoly game with heterogeneous players," Physica A. Statistical Mechanics and its Applications, vol. 320, no. 1-4, pp. 512-524, 2003.

[14] J. X. Zhang, Q. L. Da, and Y. H. Wang, "Analysis of nonlinear duopoly game with heterogeneous players," Economic Modelling, vol. 24, no. 1, pp. 138-148, 2007.

[15] F. Tramontana, "Heterogeneous duopoly with isoelastic demand function," Economic Modelling, vol. 27, no. 1, pp. 350-357, 2010.

[16] N. Angelini, R. Dieci, and F. Nardini, "Bifurcation analysis of a dynamic duopoly model with heterogeneous costs and behavioural rules," Mathematics and Computers in Simulation, vol. 79, no. 10, pp. 3179-3196, 2009.

[17] J. Ma and L. Xie, "The comparison and complex analysis on dual-channel supply chain under different channel power structures and uncertain demand," Nonlinear Dynamics. An International Journal of Nonlinear Dynamics and Chaos in Engineering Systems, vol. 83, no. 3, pp. 1379-1393, 2016.

[18] Y. Fan, T. Xie, and J. Du, "Complex dynamics of duopoly game with heterogeneous players: a further analysis of the output model," Applied Mathematics and Computation, vol. 218, no. 15, pp. 7829-7838, 2012.

[19] Z. Ding, Q. Hang, and L. Tian, "Analysis of the dynamics of Cournot team-game with heterogeneous players," Applied Mathematics and Computation, vol. 215, no. 3, pp. 1098-1105, 2009.

[20] A. Matsumoto and F. Szidarovszky, "Nonlinear delay monopoly with bounded rationality," Chaos Solitons \& Fractals, vol. 45, pp. 507-519, 2012.

[21] A. Matsumoto and F. Szidarovszky, Boundedly Rational Monopoly with Single Continuously Distributed Time Delay, Springer International Publishing, 2014.

[22] A. Matsumoto and F. Szidarovszky, "Discrete-time delay dynamics of boundedly rational monopoly," Decisions in Economics and Finance. A Journal of Applied Mathematics, vol. 37, no. 1, pp. 53-79, 2014.

[23] S. Z. Hassan, "On delayed dynamical duopoly," Applied Mathematics and Computation, vol. 151, no. 1, pp. 275-286, 2004.

[24] M. T. Yassen and H. N. Agiza, "Analysis of a duopoly game with delayed bounded rationality," Applied Mathematics and Computation, vol. 138, no. 2-3, pp. 387-402, 2003.

[25] J. Peng, Z. Miao, and F. Peng, "Study on a 3-dimensional game model with delayed bounded rationality," Applied Mathematics and Computation, vol. 218, no. 5, pp. 1568-1576, 2011.

[26] Z. Ding, X. Zhu, and S. Jiang, "Dynamical Cournot game with bounded rationality and time delay for marginal profit," Mathematics and Computers in Simulation, vol. 100, pp. 1-12, 2014.

[27] A. A. Elsadany and A. E. Matouk, "Dynamic cournot duopoly game with delay," Journal of Complex Systems, vol. 2014, Article ID 384843, 7 pages, 2014.

[28] A. A. Elsadany, "A dynamic Cournot duopoly model with different strategies," Journal of the Egyptian Mathematical Society, vol. 23, no. 1, pp. 56-61, 2015.
[29] J. Ma and F. Si, "Complex dynamics of a continuous Bertrand duopoly game model with two-stage delay," Entropy. An International and Interdisciplinary Journal of Entropy and Information Studies, vol. 18, no. 7, 2016.

[30] J. Ma and F. Wu, "The application and complexity analysis about a high-dimension discrete dynamical system based on heterogeneous triopoly game with multi-product," Nonlinear Dynamics. An International Journal of Nonlinear Dynamics and Chaos in Engineering Systems, vol. 77, no. 3, pp. 781-792, 2014.

[31] J. Ma and H. Wang, "Complexity analysis of dynamic noncooperative game models for closed-loop supply chain with product recovery," Applied Mathematical Modelling. Simulation and Computation for Engineering and Environmental Systems, vol. 38, no. 23, pp. 5562-5572, 2014.

[32] Z. W. Ding, Q. Wang, and S. M. Jiang, "Analysis on the dynamics of a Cournot investment game with bounded rationality," Economic Modelling, vol. 39, pp. 204-212, 2014.

[33] A. A. Elsadany, "Dynamics of a delayed duopoly game with bounded rationality," Mathematical and Computer Modelling, vol. 52, no. 9-10, pp. 1479-1489, 2010.

[34] L. U. Yali, "Dynamics of a delayed Duopoly game with increasing marginal costs and bounded rationality strategy," Procedia Engineering, vol. 15, pp. 4392-4396, 2011.

[35] S. Elaydi, An Introduction to Difference Equations, 3rd Edition, Springer, New York, NY, USA, 2005.

[36] E. M. Elabbasy, H. N. Agiza, and A. A. Elsadany, "Analysis of nonlinear triopoly game with heterogeneous players," Computers \& Mathematics with Applications, vol. 57, pp. 488-499, 2009.

[37] K. Pyragas, "Continuous control of chaos by self-controlling feedback," Physics Letters A, vol. 170, no. 6, pp. 421-428, 1992.

[38] J. A. Holyst and K. Urbanowicz, "Chaos control in economical model by time-delayed feedback method," Physica A: Statistical Mechanics and its Applications, vol. 287, no. 3-4, pp. 587-598, 2000. 


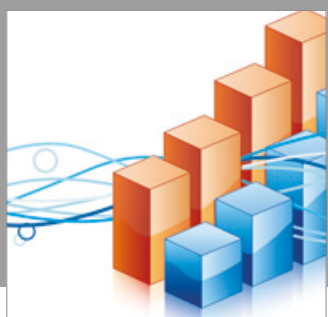

Advances in

Operations Research

vatersals

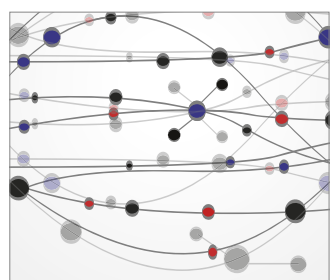

\section{The Scientific} World Journal
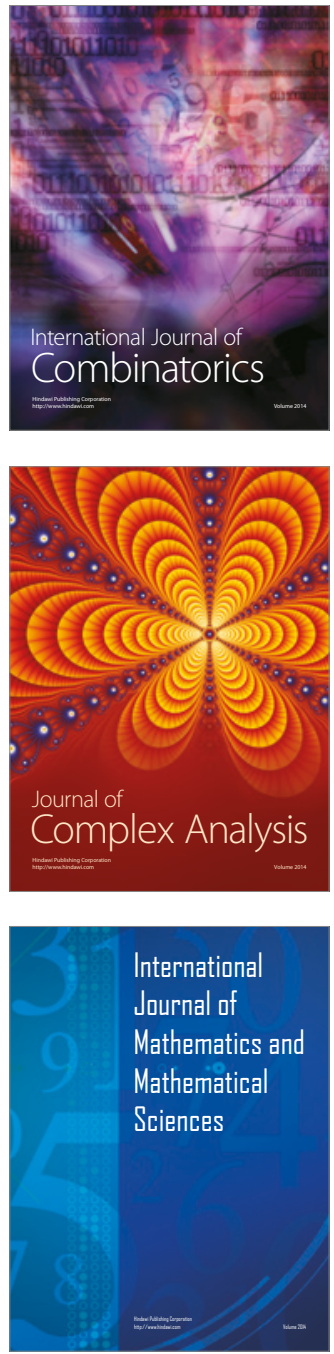
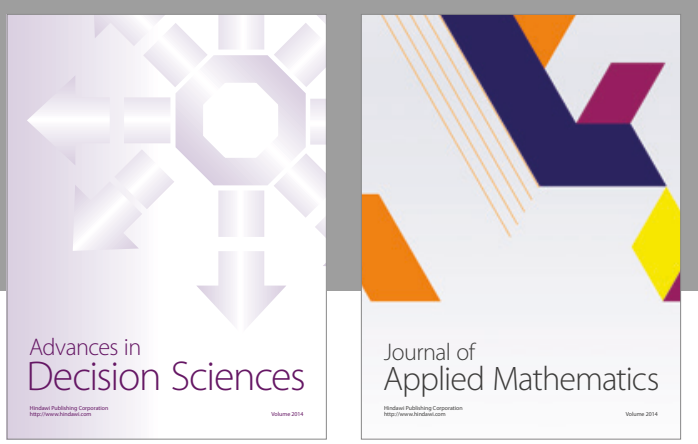

Algebra

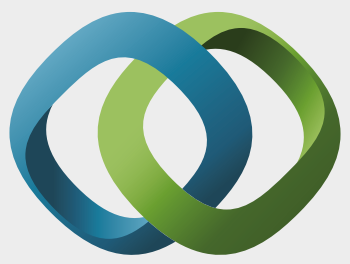

\section{Hindawi}

Submit your manuscripts at

https://www.hindawi.com
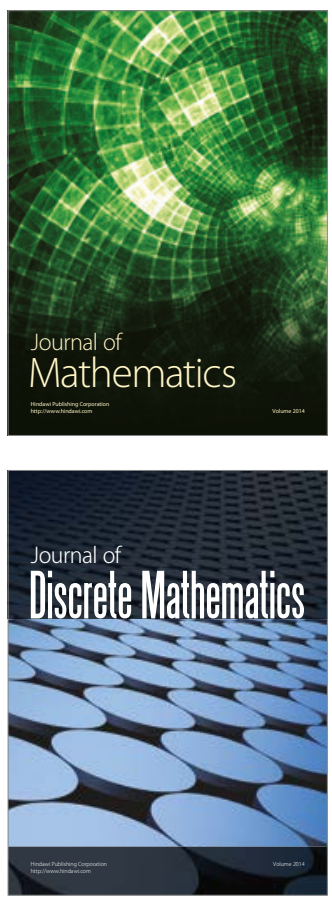

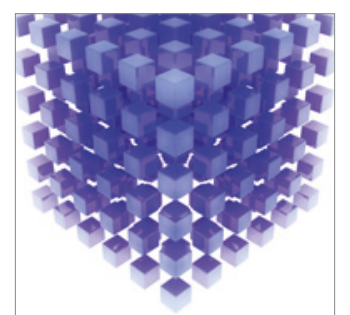

Mathematical Problems in Engineering
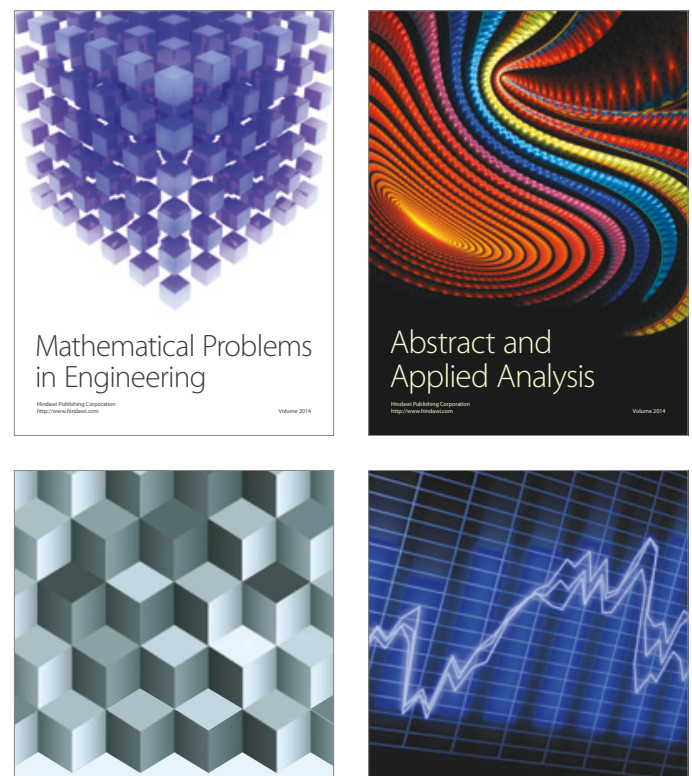

Journal of

Function Spaces

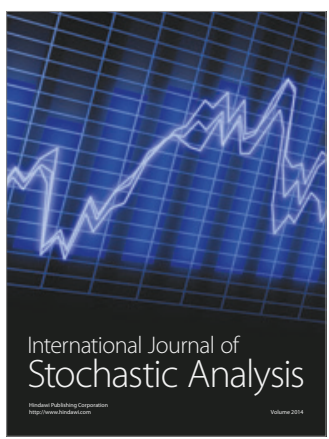

Probability and Statistics
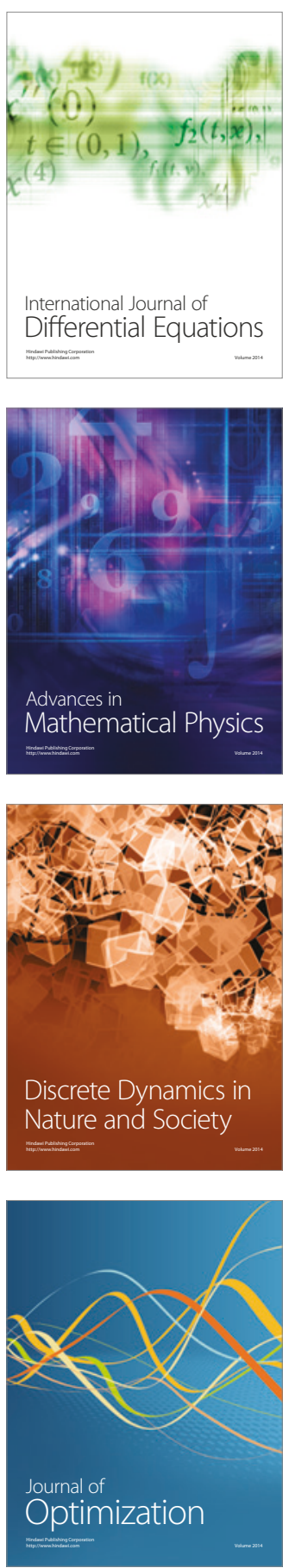